\title{
Kurutulmuş Meyvelerde Aflatoksin ve Okratoksin A Varlığının ve Sağlık Üzerine Etkilerinin Değerlendirilmesi
}

\author{
Okan Fatih Gürhayta1 Özlem Çağınd $2^{2 *}$ \\ ${ }^{1}$ Celal Bayar Üniversitesi, Gıda Mühendisliği Bölümü, Muradiye, Manisa, 05334968317 \\ ${ }^{2}$ Celal Bayar Üniversitesi, Gıda Mühendisliği Bölümü, Muradiye, Manisa, 0236 2012263, 0236 2412143, \\ ozlem.cagindi@cbu.edu.tr \\ *iletişimden sorumlu yazar / Corresponding author \\ Geliş / Recieved: 7 Eylül (September) 2015 \\ Kabul / Accepted: 28 Aralık (December) 20015 \\ DOI: http://dx.doi.org/10.18466/cbujos.90850
}

\begin{abstract}
Aflatoksin ve okratoksin A Aspergillus ve Penicillium cinsi küfler tarafından üretilen ikincil metabolit ürünlerdir. Bilinen 400 ‘den fazla mikotoksin arasında aflatoksinler ve okratoksin A insan sağlığı açısından en tehlikeli olanlarıdır. 20'den fazla aflatoksin çeşidi içerisinde aflatoksin $B_{1}$, aflatoksin $B_{2}$, aflatoksin $G_{1}$ ve aflatoksin $\mathrm{G}_{2}$ doğal olarak üretilen başlıcalarıdır. Kurutulmuş ürünler ile ilgili önemli sorunlardan biri küf kontaminasyonudur. Küf kontaminasyonu, insan sağlığı, gıda güvenliği ve ekonomik açıdan önem teşkil eder ve kurutulmuş meyveler de küf gelişimine uygun ürünlerdir. Meyvelerin kurutularak muhafaza edilmesi eski çă̆lardan beri kullanılan önemli gıda saklama yöntemlerinden biri olmakla birlikte yetersiz kurutma ve uygun olmayan depolama koşulları, kurutulmuş meyvelerde aflatoksin ve okratoksin A oluşumuna neden olabilmektedir. Yapılan çeşitli çalışmalar aflatoksin ve okratoksin A'nın karsinojenik, genotoksik, teratojenik, bağışıklık sistemini baskılayıcı ve nefrotoksik özellikte olduğunu göstermektedir. İncelenen çalışmalar meyvelerin kurutulması sırasında başta hammadde seçimine ve kurutma işlemine gereken önemin verilmesinin önemini ortaya çıkarmıştır. Gerekli ve yeterli önemin verilmesi ile sağlık üzerine olumsuz etkileri olan bu toksinlerin varlığının önüne geçilebileceği düşünülmektedir. $\mathrm{Bu}$ çalışmada kurutulmuş meyvelerde aflatoksin ve okratoksin A'nın varlığı ile sağlık üzerine etkileri derlenmiştir.
\end{abstract}

Özet

Anahtar Kelimeler - $\mathrm{AFB}_{1}$, Aflatoksinler, kurutulmuş meyveler, okratoksin A, sağlık etkileri

\section{Evaluation of the Occurrence and Health Implications of Aflatoxin and Ochratoxin A in Dried Fruits}

\begin{abstract}
Aflatoxins and ocratoxin A are secondary metabolites mainly produced by mold of genera Aspergillus, Penicilliu. Aflatoxins and Ocratoxin A are the most dangerous ones in between known 400 toxins. Aflatoxin $B_{1}$, aflatoxin $B_{2}$, aflatoxin $G_{1}$ and aflatoxin $G_{2}$ are the main ones produced naturally between 20 types of aflatoxins. Mold contamination is one of the main problems about dried foods. Mold contamination plays an important role in human health, food safety and economy. Dried fruits are also suitable for mold contamination. Preserving fruits by drying is an effective and ancient method but inefficient drying and inappropriate storage conditions, may cause aflatoxins and ocratoxin A production in dried fruits. Various studies indicate that the mycotoxins are carcinogenic, genotoxic, teratogenic, immunotoxic and nephrotoxic. Literature studies have shown that raw material selection and drying process parameters are the key elements in fruit drying. It is known that mycotoxin formation which have negative effects on human health can be prevented by providing adequate and appropriate drying conditions. Aflatoxins and ochratoxin $\mathrm{A}$ in dried fruits and their effects on health are reviewed in this paper.
\end{abstract}

Keywords - AFB1, Aflatoxins, dried fruits, health effects, ochratoxin A 
CBÜ Fen Bil. Dergi., Cilt 12, Sayı 2, 327-338 s

\section{Giriş}

Mikotoksin, pek çok işlenmiş veya işlenmemiş gıdalarda bulunan, insan ve hayvan sağlığını tehdit eden bazı küf türlerinin metabolitleri için kullanılan bir terimdir [1]. Hasat öncesi ve sonrası koşullarda tarımsal ürünleri kontamine edebilen bu toksik metabolitler insan ve hayvanlarda kanserojen, mutajenik, teratojenik, aterojenik ve östrojenik etkiler gibi akut ve kronik etkilere neden olabilmektedirler $[2,3]$. Günümüzde 100 'den fazla toksijenik küf tarafından üretildiği bilinen 400'den fazla çeşit mikotoksin varlığı bildirilmiştir [4].

Mikotoksinler küfler tarafından sentezlendikten sonra, gidanın nem, $\mathrm{pH}$ ve su aktivitesi (aw) gibi fiziksel değerlerinin dış etkenler sebebiyle değişmesine karşı küflere nazaran daha dirençlidirler. Mikotoksinler, dayanıklılığı sayesinde ortamda küflerin olmaması halinde de varlıklarını sürdürebilirler. Mikotoksijenik potansiyel küfün tür ve çeşidine, gıda maddesinin bileşimine ve nem ile sıcaklık gibi çevresel faktörlere bağlıdır [5].

$\mathrm{Bu}$ toksinler belirli nem ve sıcaklık koşullarında Aspergillus, Penicillium ve Fusarium gibi bazı küfler tarafından oluşturulurlar [6,7]. En sık karşılaşılan mikotoksinler aflatoksin (AF), okratoksin, trikotesenler, zeranol, patulin, siklopiazonik asit ve fumonisin olarak siralanabilir [7]. Bilinen mikotoksinler arasında aflatoksinler insan sağlığ 1 açısından en tehlikeli olanlardır [8]. Meyve ve işlenmiş meyve ürünlerinde görülen başlıca mikotoksinler ise Aflatoksin $\mathrm{B}_{1}\left(\mathrm{AFB}_{1}\right)$, aflatoksin $\mathrm{B}_{2}\left(\mathrm{AFB}_{2}\right)$, aflatoksin $\mathrm{G}_{1}\left(\mathrm{AFG}_{1}\right)$, aflatoksin $\mathrm{G}_{2}\left(\mathrm{AFG}_{2}\right)$ ve okratoksin $\mathrm{A}$ (OTA), patulin ve Alternaria toksinleridir $[5,9,10]$.

$\mathrm{Bu}$ makalede, kurutulmuş meyvelerdeki yüksek toksisiteye sahip ve yaygın kontaminantlar arasında yer alan aflatoksin ve okratoksin A 'nın varlığı ile sağlık üzerine etkileri incelenecektir.

\section{Meyvelerin Kurutulması ve Mikotoksin Oluşumu}

Gidaların kurutularak muhafaza edilmesi eski çağlardan beri kullanılan önemli gıda saklama yöntemlerinden birisidir. $\mathrm{Bu}$ amaçla ülkemizde de genellikle güneşte kurutmadan yararlanılmaktadır. Coğrafi konumu itibariyle özellikle Ege, Akdeniz ve Güneydoğu Anadolu bölgelerinde meyveler güneş 1şığ1 altında kurutularak saklanmakta veya ticari
CBU J. of Sci., Volume 12, Issue 2, p 327-338

olarak piyasaya sürülmektedir. Güneşte kurutmanın yanı sıra ticari amaçlar için yapay kurutma da kullanılmaktadır. Yapay kurutma ile daha kaliteli son ürün ve üstün pişme özellikleri elde edilmesine karşın kurulum maliyeti diğer yönteme göre daha yüksektir.

Meyve kurutma aşamaları ürüne göre değişmekle birlikte genel olarak ayıklama, yıkama, kabuk soyma, dilimleme-bölme ve çekirdek çıkartma olarak sıralanabilmektedir. Üzümlerde nem düzeyi \% 15-20, eriklerde \% 16-20, kayısılarda \% 15-18, şeftalilerde \% 25-28 ve elmalarda \% 18-20 seviyelerine düşünce kurutma işlemine son verilebilir. [11]. Yetersiz kurutma ya da uygun olmayan depolama koşulları nedeniyle kurutulmuş meyveler küf kontaminasyonuna ve dolayisiyla mikotoksin oluşumuna hassas ürünlerdir. Kurutulmuş meyvelerdeki mikotoksin oluşumu hasat öncesi, hasat esnası, kurutma, paketleme ve depolama aşamalarının herhangi birinde gerçekleşebilmektedir. Hasat sırasında ürünün zedelenmesi ile uygun olmayan paketleme, depolama, kurutma ve taşıma işlemleri artan mikotoksin riskiyle birlikte fungal gelişimi teşvik etmektedir. Ürünün su aktivitesi değeri küf gelişimini önleyecek seviyeye kadar düşürüldükten sonra mikotoksin oluşumu riski önemli ölçüde azaltılmış olmaktadır [12].

Kurutulmuş meyveler içerdikleri yüksek şeker içeriği, toplanma yöntemi ve kurutma koşulları nedeniyle küf gelişimine ile aflatoksin ve okratoksin A oluşumuna oldukça müsaittirler. Ayrıca meyvenin kurutma esnasinda toprakla temas etmesi ve çevreden böceklerin istilası sebebiyle kontamine riski artmaktadır [13]. Aflatoksin ve okratoksin A mikotoksinlerinin küf türleri ve ilişkili gıdalar Tablo 1 'de gösterilmektedir.

Findık, Antep fıstığı, yer fıstığı, pul biber, kurutulmuş incir, kurutulmuş üzüm ve diğer kurutulmuş meyveler başta olmak üzere mısır buğday, süt ve süt ürünleri, elma suyu ve şarap aflatoksin ve okratoksin A açısından riskli grup içerisinde yer almaktadır $[14,15]$.

\section{Aflatoksinler}

400'den fazla mikotoksin çeşidi olmasına karşın bunlardan en tehlikelileri yüksek toksik etkileri nedeniyle aflatoksinlerdir [18]. 27-38 ${ }^{\circ} \mathrm{C}$ arası sıcaklık 
CBÜ Fen Bil. Dergi., Cilt 12, Sayı 2, 327-338 s

CBU J. of Sci., Volume 12, Issue 2, p 327-338

Tablo 1. Aflatoksin ve okratoksin A mikotoksinlerinin küf türleri ve ilişkili gıdalar $[16,17]$

Mikotoksin

Aflatoksinler

Okratoksin A
Üretici Küf Türleri

Aspergillus flavus, Aspergillus. parasiticus

Aspergillus ochraceus, Aspergillus versicolor, Pénicillium viridicatum Pénicillium cyclopium
Bulunabileceği Gıdalar

Tahıl taneleri (buğday, mısır, arpa), yer fıstığı, antepfıstığı, fındık, kırmızıbiber, süt ve süt ürünleri, incir ve diğger bazı meyveler Tahıl taneleri (buğday, mısır, arpa), yer fıstığı̆, kahve çekirdeği, fındık
0.99 aw değeri ve yüksek bağıl nem (\% 85) koşulları Aspergillus cinsi küflerin gelişmesi için uygun şartlardır. Aflatoksin üretilmesi $13-40{ }^{\circ} \mathrm{C}$ (optimum 30 ${ }^{\circ} \mathrm{C}$ ) sicaklık ve 0.95 aw değeri gibi özel ortam koşullarında gerçekleştirilmektedir [5]. Ultraviyole 1ş1k altında mavi floresans verenler $A F B_{1}$ ve $A F B_{2}$, yeşil floresans verenler ise $A_{F}$ ve $A_{1} G_{2}$ 'dir. Aflatoksinlerin moleküler yapıları Şekil 1'de verilmiştir. Aflatoksinlerin canlı organizmalarda yarattığı toksik etki derecesi büyükten küçüğe doğru sırasiyla $\mathrm{AFB}_{1}, \mathrm{AFG}_{1}, \mathrm{AFB}_{2}$ ve $\mathrm{AFG}_{2}$ şeklindedir [18]. Aflatoksinler çoğunlukla Aspergillus flavus, Aspergillus parasiticus ve Aspergillus nomius suşları tarafından üretilmekte olup A.flavus sadece B tipi aflatoksinleri

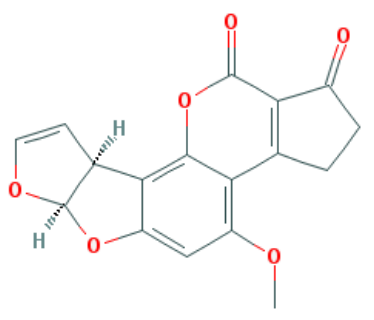

$\mathrm{AFB}_{1}$

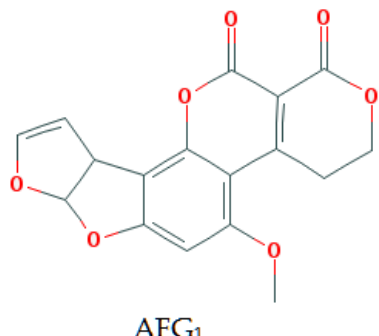

$\mathrm{AFG}_{1}$ üretebilirken diğer iki tür hem $G$ hem de $B$ tipi aflatoksinleri üretebilmektedir [19]. Aflatoksin $B_{1}$ en toksik olan aflatoksin olarak kabul edilmektedir. Aflatoksinler oldukça istikrarlı olup kavurma, çektirme (ekstrüzyon) ve pişirme gibi ağır işlemlere bile direnç gösterebilmektedir [12]. Bazı substratlar küf gelişimi ve aflatoksin oluşumu için oldukça elverişli olabilmektedirler. Tahıllar, yağlı tohumlar, baharatlar ve sert kabuklu meyvelerin aflatoksinler ile doğal yollarla kontamine olmasına pek çok ülkede yaygın şekilde rastlanılmaktadır [20]. $\mathrm{AFB}_{1}, \mathrm{AFB}_{2}$, $\mathrm{AFG}_{1}$ ve $\mathrm{AFG}_{2}$ 'ye genellikle badem, fistık, misır, baharatlar, incir ve bunların işlenmiş ürünleri gibi yağlı gidalarda rastlanmaktadır [5].

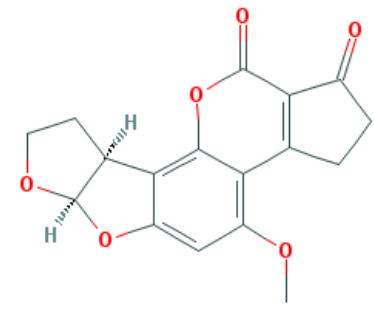

$\mathrm{AFB}_{2}$

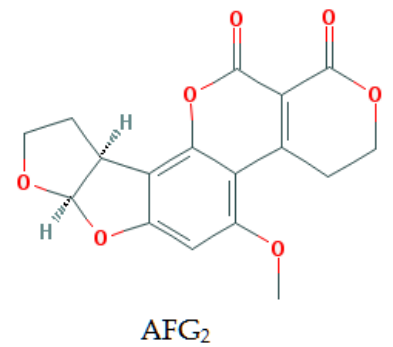

Şekil 1: $\mathrm{AFB}_{1}, \mathrm{AFB}_{2}, \mathrm{AFG}$ 1 ve $\mathrm{AFG}_{2}$ 'nin moleküler yapıları [21-24]

Aflatoksinlerin canlı organizmalarda yarattı̆g toksik etki derecesi büyükten küçüğe doğru sırasıyla $A F B 1$, $\mathrm{AFG}_{1}, \mathrm{AFB}_{2}$ ve $\mathrm{AFG}_{2}$ şeklindedir [18]. Aflatoksinler çoğunlukla Aspergillus flavus, Aspergillus parasiticus ve Aspergillus nomius suşları tarafından üretilmekte olup A.flavus sadece B tipi aflatoksinleri üretebilirken diğer 
CBÜ Fen Bil. Dergi., Cilt 12, Say1 2, 327-338 s

iki tür hem $G$ hem de $B$ tipi aflatoksinleri üretebilmektedir [19]. Aflatoksin $B_{1}$ en toksik olan aflatoksin olarak kabul edilmektedir. Aflatoksinler oldukça istikrarlı olup kavurma, çektirme ve pişirme gibi ağır işlemlere bile direnç gösterebilmektedir [12]. Bazı substratlar küf gelişimi ve aflatoksin oluşumu için oldukça elverişli olabilmektedirler. Tahıllar, yağlı tohumlar, baharatlar ve sert kabuklu meyvelerin aflatoksinler ile doğal yollarla kontamine olmasina pek çok ülkede yaygın şekilde rastlanılmaktadır [20]. $\mathrm{AFB}_{1}, \mathrm{AFB}_{2}, \mathrm{AFG}_{1}$ ve $\mathrm{AFG}_{2}$ 'ye genellikle badem, fistık, mısır, baharatlar, incir ve bunların işlenmiş ürünleri gibi yağlı gıdalarda rastlanmaktadır [5].

Kurutulmuş meyvelerde aflatoksin kontaminasyonu ile ilgili çeşitli çalışmalar yapılmış olup [25-29], kurutulmuş üzüm [25,27,28,30-32], kurutulmuş incir [26,28,29,31,32], hurma [20,29,33], kurutulmuş kayısı [18,33-35], kurutulmuş erik [18,20,35,36], kurutulmuş dut [20] ve kurutulmuş kirazda [18] aflatoksin kontaminasyonu bildirilmiştir. Kurutulmuş meyvelerde aflatoksinler ile ilgili yapılan çalışmalar Tablo 2'de verilmektedir. Masood ve ark. [31] 21 adet kurutulmuş eriği aflatoksin kontaminasyonu açısından incelemiş ve 8 tanesinde kontaminasyon tespit etmişlerdir. Kontamine olan 8 örnekten 4 'ü $\mathrm{AFB}_{1}$ açısından, 2'si $\mathrm{AFB}_{1}, \mathrm{AFB}_{2}, \mathrm{AFG}_{1}$ ve $\mathrm{AFG}_{2}$ toplamı açısından Avrupa Birliği sınır değerlerini aştı̆̆1 görülmüştür. İlker [26], 20 adet incir örneğinde toplam aflatoksin miktarını incelemiş ve örneklerde 0.2 ppb ölçüm alt sınırı dahilinde kirlilik tespit edemediklerini bildirmişlerdir.

\section{Okratoksin A}

Okratoksin A, beyaz kristal toz yapısında ve sıcaklığa karşı oldukça dayanıklıdır. Okratoksin A'nın moleküler yapısı Şekil 2'de gösterilmektedir. Okratoksin A üreten ana küf türleri $A$. ochraceus, $A$. carbonarius, A. melleus, A. sclerotiorum, A. sulphureus, $P$.

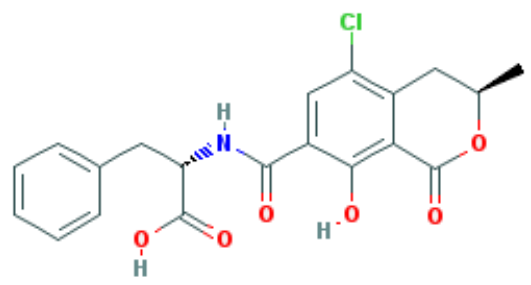

Şekil 2: Okratoksin A'nın moleküler yapısı [39]
CBU J. of Sci., Volume 12, Issue 2, p 327-338

verrucossum 'dur. Ayrica Aspergillus niger ve $P$. purpurescens de önemli OTA üreticilerindendir $[37,38]$. Okratoksin A, Aspergillus cinsi küfler tarafından tropikal ve alt tropikal bölgelerde; Penicillum cinsi küfler tarafından ise ılıman ve soğuk bölgelerde üretilmektedir. Bu küf cinsleri çoğu zaman çeşitli toksinleri (okratoksin A, B ve C) eş zamanlı olarak üretmekte ve bu da sinerjik etkiye neden olabilmektedir [33].

Hububat ürünlerinin $121{ }^{\circ} \mathrm{C}$ sicaklık ve $1 \mathrm{~atm}$ basınç altında 3 saat süreyle tutulmaları halinde OTA'nın \%35'inin etkinliğini sürdürdüğü bildirilmektedir. Okratoksin B, OTA'dan daha az toksik olup karaciğer hücrelerindeki protein sentezini engellemektedir [40].

A. ochraceus'un arpada gelişebildiği sıcaklık aralığı 8$37{ }^{\circ} \mathrm{C}$ iken optimum gelişmesi $25-30{ }^{\circ} \mathrm{C}$ civarında gerçekleşmiştir. En yüksek OTA üretimi 0.98 aw değerinde gerçekleşmiştir. En düşük OTA üretimi 0.83-0.87 aw aralığında, en yüksek OTA üretimi 0.96$0.98 \mathrm{aw}$ aralığında elde edilmiş olup bu aralıkta OTA üretiminin aw değeriyle doğru orantılı olarak artış gösterdiği gözlemlenmiştir [2].

Penicillium verrucosum 'un optimum gelişme sıcaklığı $20{ }^{\circ} \mathrm{C}$, aw aralığı 6.0-7.0 ve $\mathrm{pH}$ aralığı arasındadır ve $P$. verrucosum, okratoksini $0{ }^{\circ} \mathrm{C}$ 'den $31^{\circ} \mathrm{C}$ 'ye kadar olan bütün sıcak aralığında üretebilmektedir [41]. OTA'ya genellikle kakao, kahve çekirdeği, tahıllar, kurutulmuş meyveler, şarap, bira, üzüm, kabuklu yemişler ve baharatlarda rastlanmaktadır [13,42,43].

Kurutulmuş meyvelerde okratoksin A varlığının araştırılması ile ilgili yapılan çalışmaların özet bilgisi Tablo 3'te gösterilmektedir. Yapılan çalışmalarda kurutulmuş incir [28,44,45], kurutulmuş kayısı $[32,37,44]$, hurma [32,45], kurutulmuş üzüm $[44,45]$, kurutulmuş ayva [46] ve kurutulmuş hindistancevizinde OTA varlığ ve Sumbali [46] incelediği 25 kurutulmuş ayva örneğinin 8'inde OTA tespit etmiş; Fakoor Janati ve ark. [37] ise araştırdığı 15 kurutulmuş erik örneğinin 3'ünde OTA tespit etmiştir. 
CBÜ Fen Bil. Dergi., Cilt 12, Sayı 2, 327-338 s

CBU J. of Sci., Volume 12, Issue 2, p 327-338

Tablo 2. Bazı kurutulmuş meyvelerde aflatoksin varlığı ile ilgili yapılan çalışmalar

\begin{tabular}{|c|c|c|c|c|c|}
\hline $\begin{array}{l}\text { Örnek } \\
\text { Tipi }\end{array}$ & $\begin{array}{l}\text { Örnek } \\
\text { Sayıs }\end{array}$ & Mikotoksin Tipi & $\begin{array}{l}\text { Pozitif Örnek } \\
\text { Sayısı }\end{array}$ & $\begin{array}{c}\text { AB Limitlerini Aşan Örnek } \\
\text { Sayısı }\end{array}$ & Kaynak \\
\hline Hurma & 48 & $\mathrm{AFB}_{1}+\mathrm{AFB}_{2}+\mathrm{AFG}_{1}+\mathrm{AFG}_{2}$ & 22 & 0 & [32] \\
\hline Hurma & \multirow{2}{*}{15} & $\mathrm{AFB}_{1}$ & 9 & 5 & \multirow{2}{*}{ [31] } \\
\hline Hurma & & $\mathrm{AFB}_{1}+\mathrm{AFB}_{2}+\mathrm{AFG}_{1}+\mathrm{AFG}_{2}$ & 9 & 3 & \\
\hline Hurma & 20 & $\mathrm{AFB}_{1}+\mathrm{AFB}_{2}+\mathrm{AFG}_{1}+\mathrm{AFG}_{2}$ & 2 & 0 & [28] \\
\hline $\begin{array}{l}\text { Kuru } \\
\text { Üzüm }\end{array}$ & \multirow{3}{*}{71} & $\mathrm{AFB}_{1}$ & 6 & 6 & \multirow{3}{*}[32]{} \\
\hline $\begin{array}{l}\text { Uzum } \\
\text { Kuru }\end{array}$ & & & & & \\
\hline Üzüm & & $\mathrm{AFG}_{2}$ & 5 & 0 & \\
\hline $\begin{array}{l}\text { Kuru } \\
\text { Üzüm }\end{array}$ & 16 & $\mathrm{AFB}_{1}+\mathrm{AFB}_{2}+\mathrm{AFG}_{1}+\mathrm{AFG}_{2}$ & 3 & 0 & [27] \\
\hline $\begin{array}{l}\text { Kuru } \\
\text { Üzüm }\end{array}$ & 10 & $\mathrm{AFB}_{1}+\mathrm{AFB}_{2}+\mathrm{AFG}_{1}+\mathrm{AFG}_{2}$ & 2 & 1 & [28] \\
\hline $\begin{array}{l}\text { Kuru } \\
\text { Üzüm }\end{array}$ & 43 & $\mathrm{AFB}_{1}+\mathrm{AFB}_{2}+\mathrm{AFG}_{1}+\mathrm{AFG}_{2}$ & 3 & 0 & [25] \\
\hline $\begin{array}{l}\text { Kuru } \\
\text { Üzüm }\end{array}$ & \multirow[b]{2}{*}{21} & $\mathrm{AFB}_{1}$ & 9 & 4 & \multirow[b]{2}{*}{ [31] } \\
\hline $\begin{array}{l}\text { Kuru } \\
\text { Üzüm }\end{array}$ & & $\mathrm{AFB}_{1}+\mathrm{AFB}_{2}+\mathrm{AFG}_{1}+\mathrm{AFG}_{2}$ & 9 & 0 & \\
\hline Kuru İncir & 28 & $\mathrm{AFG}_{1}$ & 4 & 0 & [32] \\
\hline Kuru İncir & 20 & $\mathrm{AFB}_{1}+\mathrm{AFB}_{2}+\mathrm{AFG}_{1}+\mathrm{AFG}_{2}$ & 0 & 0 & [26] \\
\hline Kuru İncir & 10 & $\mathrm{AFB}_{1}+\mathrm{AFB}_{2}+\mathrm{AFG}_{1}+\mathrm{AFG}_{2}$ & 5 & 3 & [28] \\
\hline Kuru İncir & 19 & $\mathrm{AFB}_{1}+\mathrm{AFB}_{2}$ & 11 & 1 & [25] \\
\hline Kuru İncir & 45 & $\mathrm{AFB}_{1}+\mathrm{AFB}_{2}+\mathrm{AFG}_{1}+\mathrm{AFG}_{2}$ & 4 & 0 & [29] \\
\hline Kuru İncir & \multirow{2}{*}{22} & $\mathrm{AFB}_{1}$ & 7 & 4 & \multirow{2}{*}{ [31] } \\
\hline Kuru İncir & & $\mathrm{AFB}_{1}+\mathrm{AFB}_{2}+\mathrm{AFG}_{1}+\mathrm{AFG}_{2}$ & 7 & 2 & \\
\hline $\begin{array}{l}\text { Kuru } \\
\text { Kayıs1 }\end{array}$ & 27 & $\mathrm{AFB}_{1}+\mathrm{AFB}_{2}+\mathrm{AFG}_{1}+\mathrm{AFG}_{2}$ & 3 & - & [32] \\
\hline $\begin{array}{l}\text { Kuru } \\
\text { Kayıs1 }\end{array}$ & 16 & $\mathrm{AFB}_{1}+\mathrm{AFB}_{2}+\mathrm{AFG}_{1}+\mathrm{AFG}_{2}$ & 4 & 1 & [27] \\
\hline $\begin{array}{l}\text { Kuru } \\
\text { Kayıs1 }\end{array}$ & 30 & $\mathrm{AFB}_{1}+\mathrm{AFB}_{2}+\mathrm{AFG}_{1}+\mathrm{AFG}_{2}$ & 7 & - & [37] \\
\hline $\begin{array}{l}\text { Kuru } \\
\text { Kayıs1 }\end{array}$ & 20 & $\mathrm{AFB}_{1}+\mathrm{AFB}_{2}+\mathrm{AFG}_{1}+\mathrm{AFG}_{2}$ & 4 & 1 & {$[28]$} \\
\hline $\begin{array}{l}\text { Kuru } \\
\text { Kayıs1 }\end{array}$ & 20 & $\mathrm{AFB}_{1}$ & 7 & 3 & \multirow{2}{*}[31]{} \\
\hline $\begin{array}{l}\text { Kuru } \\
\text { Kayis1 }\end{array}$ & 20 & $\mathrm{AFB}_{1}+\mathrm{AFB}_{2}+\mathrm{AFG}_{1}+\mathrm{AFG}_{2}$ & 7 & 1 & \\
\hline Kuru Erik & 27 & $\mathrm{AFB}_{1}+\mathrm{AFB}_{2}+\mathrm{AFG}_{1}+\mathrm{AFG}_{2}$ & 7 & 7 & [32] \\
\hline Kuru Erik & 16 & $\mathrm{AFB}_{1}+\mathrm{AFB}_{2}+\mathrm{AFG}_{1}+\mathrm{AFG}_{2}$ & 3 & 0 & [27] \\
\hline Kuru Erik & 15 & $\mathrm{AFB}_{1}+\mathrm{AFB}_{2}+\mathrm{AFG}_{1}+\mathrm{AFG}_{2}$ & 2 & - & [37] \\
\hline Kuru Erik & \multirow{2}{*}{21} & $\mathrm{AFB}_{1}$ & 8 & 4 & \multirow{2}{*}{ [31] } \\
\hline Kuru Erik & & $\mathrm{AFB}_{1}+\mathrm{AFB}_{2}+\mathrm{AFG}_{1}+\mathrm{AFG}_{2}$ & 8 & 2 & \\
\hline Kuru Kiraz & 16 & $\mathrm{AFB}_{1}+\mathrm{AFB}_{2}+\mathrm{AFG}_{1}+\mathrm{AFG}_{2}$ & 5 & 0 & [27] \\
\hline Kuru Dut & 15 & $\mathrm{AFB}_{1}+\mathrm{AFB}_{2}+\mathrm{AFG}_{1}+\mathrm{AFG}_{2}$ & 4 & 0 & [28] \\
\hline
\end{tabular}


CBÜ Fen Bil. Dergi., Cilt 12, Sayı 2, 327-338 s

CBU J. of Sci., Volume 12, Issue 2, p 327-338

Tablo 3. Bazı kurutulmuş meyvelerde okratoksin A varlığı ile ilgili yapılan çalışmalar

\begin{tabular}{lcccc} 
Örnek Tipi & Örnek Sayıs1 & Pozitif Örnek Sayısı & AB Limitlerini Aşan Örnek Sayıs1 & Kaynak \\
\hline Hurma & 48 & 18 & 0 & {$[32]$} \\
Hurma & 95 & 1 & - & {$[45]$} \\
Kuru Üzüm & 71 & 18 & 0 & 2 \\
Kuru Üzüm & 109 & 48 & 2 & {$[44]$} \\
Kuru Üzüm & 53 & 28 & 2 & {$[45]$} \\
Kuru İncir & 98 & 18 & - & {$[32]$} \\
Kuru İncir & 88 & 4 & 0 & {$[44]$} \\
Kuru İncir & 28 & 5 & 0 & {$[32]$} \\
Kuru Kayısı & 20 & 1 & - & {$[37]$} \\
Kuru Kayısı & 27 & 3 & - & {$[32]$} \\
Kuru Kayısı & 30 & 1 & 7 & {$[37]$} \\
Kuru Erik & 27 & 7 & - & {$[46]$} \\
Kuru Erik & 15 & 3 & 0 &
\end{tabular}

-:ilgili veri bulunmamaktadır

Aflatoksikoz ve okratoksikozun belirtileri genel olarak toksinin türü, miktarı, maruziyet derecesi, kişinin yaşı, cinsiyeti, kilosunun yanı sıra çevresel faktörlere ve birden fazla farklı mikotoksin alımına göre değişiklik göstermektedir [40,47]. Bazı gıda maddelerinde aflatoksinler ve okratoksin A için kabul edilebilir üst limitleri Tablo 5'te yer almaktadır.

$\mathrm{Bu}$ toksinlerin insan sağlığı üzerinde akut ya da kronik hastalıklara sebep olduğu bildirilmiştir. Aflatoksinlerin insanlarda oluşturduğu akut ve kronik etkiler aflatoksikoz, okratoksinlerin oluşturdukları klinik etkiler ise okratoksikoz olarak adlandırılmaktadır [18]. Aflatoksin $B_{1}$ ve okratoksin A'nın neden oldukları hastalıklar ve sağlık etkileri Tablo 4 'te verilmektedir.

Tablo 4. Aflatoksin $B_{1}$ ve okratoksin $A^{\prime}$ nin neden oldukları hastalıklar ve sağlık etkileri [47]

\begin{tabular}{|c|c|c|}
\hline Mikotoksinler & $\begin{array}{l}\text { Neden Olduğu } \\
\text { Hastalık }\end{array}$ & Sağlık Etkisi \\
\hline $\mathrm{AFB}_{1}$ & $\begin{array}{l}\text { İnsanda primer } \\
\text { karaciğer } \\
\text { kanseri, Turkey- } \\
\text { X hastalığ } 1\end{array}$ & $\begin{array}{l}\text { Karsinojenik, } \\
\text { teratojenik }\end{array}$ \\
\hline OTA & $\begin{array}{l}\text { Domuzlarda ve } \\
\text { kümes } \\
\text { hayvanlarında } \\
\text { nefropati }\end{array}$ & $\begin{array}{l}\text { Nefropatik ve } \\
\text { karsinojenik }\end{array}$ \\
\hline
\end{tabular}

Genel olarak nemli ve sıcak iklime sahip küf gelişimine elverişli bölgelerde görülmektedir.

\subsection{Aflatoksinlerin Sağlık Üzerine Etkileri}

Aflatoksin (AF) grubu, toksik ve karsinojenik poliketit ve karmaşık biyosentetik yolla üretilen ikincil metabolitler olup [53,54], akut ve kronik toksisite göstermekte; çok çeşitli organizmalarda mutajenik, karsinojenik ve teratojenik etkiler sergilemektedir [54,55]. Aflatoksinlerin en yaygin emilimi mide-bağırsak sindirim kanalından, akciğer ve deriden gerçekleştiği, yumuşak dokularda ve hayvanların depo yağlarında birikme eğilimi gösterdiği, karaciğer, böbrekler gibi kendi biyosentezini gerçekleştiren dokularda en yüksek seviyede biriktiği bildirilmektedir. Yem yoluyla alınan aflatoksinlerin 30 dakika içerisinde midebağırsak kanalından geçerek kan dolaşımına katıldığı ve 1 saat içinde karaciğere ulaştığ görülmüştür. AF moleküllerinin karaciğer hücrelerinde bozulmaların en az 6 yolla gerçekleştiği ve tüm metabolitler içerisinde $\mathrm{AFB}_{1}$ karaciğerde kansere sebep olan en mutajen ajan olduğu bildirilmiştir [56] 
CBÜ Fen Bil. Dergi., Cilt 12, Sayı 2, 327-338 s

CBU J. of Sci., Volume 12, Issue 2, p 327-338

Tablo 5. Bazı gidaların Türkiye'de ve Avrupa Birliği (AB) üye ülkelerinde aflatoksinlerin ve okratoksin A'nın yasal limitleri [48-52]

\begin{tabular}{|c|c|c|c|c|c|c|}
\hline \multirow{2}{*}{ Gida Maddesi } & \multicolumn{3}{|c|}{$\begin{array}{l}\text { Kabul Edilebilir Üst Limit } \\
\text { (Türkiye) }(\mu \mathrm{g} / \mathrm{kg})\end{array}$} & \multicolumn{3}{|c|}{$\begin{array}{l}\text { Kabul Edilebilir Üst Limit (AB üye ülkeler } \\
(\mu \mathrm{g} / \mathrm{kg})\end{array}$} \\
\hline & $\mathrm{AFB}_{1}$ & $\begin{array}{c}\mathrm{AFB}_{1}+\mathrm{AFB}_{2}+\mathrm{AFG}_{1} \\
+\mathrm{AFG}_{2}\end{array}$ & OTA & $\mathrm{AFB}_{1}$ & $\begin{array}{c}\mathrm{AFB}_{1}+\mathrm{AFB}_{2}+\mathrm{AFG}_{1} \\
+\mathrm{AFG}_{2}\end{array}$ & OTA \\
\hline Kurutulmuş incir & \multirow{3}{*}{8} & \multirow{4}{*}{10} & - & 6 & 10 & - \\
\hline $\begin{array}{l}\text { Kurutulmuş } \\
\text { meyveler (incir } \\
\text { hariç) }\end{array}$ & & & - & \multirow[t]{2}{*}{2} & \multirow[t]{2}{*}{4} & - \\
\hline Kurutulmuş üzüm & & & 10 & & & 10 \\
\hline Baharat & 5 & & 15 & 5 & 10 & 15 \\
\hline Tahıl ve ürünleri & 2 & 4 & 3 & 2 & 4 & 3 \\
\hline $\begin{array}{l}\text { Tahıl ve ürünlerini } \\
\text { içeren bebek } \\
\text { gidaları }\end{array}$ & 0,10 & - & 0,5 & 0,10 & - & 0,5 \\
\hline Şarap & - & - & - & - & - & 2 \\
\hline Çözünebilir kahve & - & - & - & - & - & 10 \\
\hline
\end{tabular}

-:ilgili veri bulunmamaktadır

Denek hayvanları üzerinde yapılan klinik çalışmalar aflatoksinlerin son derece tesirli karsinojenler olduğunu göstermektedir. Yapilan çalışmaların sonucu olarak Uluslararası Kanser Araştırma Ajansı (IARC) $\mathrm{AFB}_{1}, \mathrm{AFB}_{2}, \mathrm{AFG}_{1}$ ve $\mathrm{AFG}_{2}{ }^{\prime}$ yi Grup 1 karsinojenlerine dahil etmiştir [34]. En toksik olanı $\mathrm{AFB}_{1}{ }^{\prime}$ dir.

Aflatoksinler vücuda az miktarlarda alınsa bile uzun zaman periyodunda aflatoksinlerin kronik vakalarına sebep olduğu bildirilmektedir. [12]. İnsanlara çalıştıkları alanlardan veya dolaylı olarak aflatoksin tüketmiş hayvanların et, süt, yumurta gibi ürünlerinden bulaşmaktadır [56,57]. Zira yapılan çalışmalar hayvanların çok az miktarda $\mathrm{AFB}_{1}$ almaları halinde toksinin özellikle karaciğer ve diğer dokular olmak üzere hayvanın süt ve yumurtasına da geçebildiğini göstermektedir [47]. Aflatoksin $B_{1}$ bulaşmış yem ile beslenen inekler, $\mathrm{AFB}_{1}{ }^{\prime} \mathrm{i}$ metabolik transformasyon ile Aflatoksin Mı'e dönüştürmektedir. Aflatoksinler ayrıca süt ineklerinin günlük verimini de etkilemektedir [58]. $\mathrm{AFB}_{1}$ ile beslenen kümes hayvanları, balık ve kemirgenlerde karaciğer hasarı tespit edilmiştir [59]. Aflatoksinlerin hayvanlarda hepatoksik etki gösterdiği ve karaciğer dokusuna zarar verdiği bildirilmiştir [59,60]. Aflatoksin maruziyeti ile karaciğer kanserinin, yapılan klinik çalışmalarda istatistiksel anlamda ilişkili oldukları bildirilmektedir [61,62].

Aflatoksinler hücre DNA'lariyla bağ kurma kapasitesine sahip olmaları nedeniyle, timik aplezi (DiGeorge Sendromu) oluşumunu tetiklemenin yanı sıra protein sentezini de etkilemektedir [20].

Aflatoksinler, bu toksik maddelere maruz kalmış insanlarda tümör oluşumunu tetikleyici, bağışıklık sistemini baskılayıc1 ve enfeksiyon direncini düşürücü etki göstermekte ve hepatit $B$ hastası kişilerde karaciğer kanserine yakalanma riskini ciddi oranda arttırmaktadır [63].

$\mathrm{AFB}_{1}{ }^{\prime}$ in toksik etkisinin görüldüğü en büyük olay (Turkey-X hastalığı) 1960 yılında İngiltere'de 100000'den fazla hindinin $\mathrm{AFB}_{1}$ bulaşmış yer fıstığ ile beslenmesi sonucu telef olmasiyla ortaya çıkmıştır [64].

Benin ve Togo'da 5 yaş altı 480 çocuk üzerinde yapılan aflatoksin maruziyeti ile ilgili bir çalışmada kandaki albüminlere bağlı aflatoksin miktarı ile çocuklarda gelişim geriliği ve kilo kaybı arasında doz-yanıt ilişkisi belirlenmiştir [65].

2004 yılında, Kenya'da yaşayan bazı insanlarda aflatoksin bulaşmış mısır tüketimi sonucu akut hepatoksisite salgınına rastlanılmış olması 
CBÜ Fen Bil. Dergi., Cilt 12, Sayı 2, 327-338 s

aflatoksinlerin zararlı etkilerine örnek gösterilmektedir [66].

\subsection{Okratoksin A'nın Sağlık Üzerine Etkileri}

Okratoksin A, gidaları sıklıkla kontamine eden zararlı bir mikotoksindir [67]. Nefrotoksik, immunosupresif, teratojenik, genotoksik ve karsinojenik özellikler göstermektedir. Hayvanlarla yapılan deneyler OTA'nın hedef organının böbrek olduğunu göstermiş, hayvanların yanı sıra insanları etkileyen çeşitli böbrek hastalıklarından da sorumlu olduğu bildirilmiştir [68,69].

OTA'nın organlar ve dokular üzerine, apoptoz indüksiyonu, oksidatif stres, protein sentezinin engellenmesi, kalsiyum homeostazı bozukluğu, transkripsiyon faktörlerinin modülasyonu gibi farklı hücresel etkileri bildirilmekle birlikte, metabolizma ve etki mekanizmaları henüz tam olarak ortaya konamamıștır. Bağırsak hücrelerinin yüksek konsantrasyonlarda OTA'ya oldukça dayanıklı oldukları saptanmış ancak beslenme faktörleri ya da belirli beslenme koşullarıyla ilişkili olarak bağırsak mukozasında OTA toksisitesinin artabileceği belirlenmiştir [67].

OTA'lı yemlerle beslenen domuz, kümes hayvanları ve diğer türlerde OTA varlığı bu hayvanların süt, karaciğer, böbreklerinde gözlemlenmiştir [70,71]. Domuzların ve kümes hayvanlarının yenilebilir kısımlarında özellikle böbrekler ve karaciğerlerinde, OTA birikimi olasılığı yüksek olmasına ragmen kaslar ve yağ dokularında daha azdır [56].

OTA'nın toksik etki mekanizmasının ATP azalmasına bağlı olarak mitokondriyel solunumun inhibisyonu, protein sentezinin azalması ve tRNA sentezinin azalması olduğu düşünülmektedir [18].

Bir çalışmada, sıçanlara OTA verilmiş ve 24 saat sonra OTA'nın böbreklerde biriktiği tespit edilmiştir [72].

OTA kaynaklı toksisite çalışmaları oksidatif stresin böbrek ve karaciğerdeki tümör oluşumunda önemli rol oynadığını göstermektedir. Bu nedenle OTA'nın karsinojenik etkisinin oksidatif hasar nedeniyle ileri geldiği düşünülmektedir [73,74].
CBU J. of Sci., Volume 12, Issue 2, p 327-338

Günümüze kadar yapılmış çalışmalarda, okratoksin A tüm hayvanlarda nefropatik etki göstermekle birlikte insanlarda ise kan serumunda yaygin olarak görülmektedir [75].

Toksikolojik klinik çalışmalarında OTA'nın genotoksik, karsinojenik, bağışıklık sistemini baskılayıcı ve nefrotoksik etkiler gösterdiği bildirilmektedir [1,76,77]. Ayrıca 1957 yılında Romanya, Bulgaristan ve Yugoslavya'yı kapsayan bölgede ortaya çıkan Endemik Balkan Nefropatisi'nin sorumlusu olarak okratoksin A gösterilmiş fakat bu iddia kesin olarak ispatlanmamıştır $[36,78,79]$. OTA'nın olumsuz olarak en çok etkilediği organ böbrektir [12,80]. OTA'nın ürotelyal ve testis kanserine neden olduğu bildirilmektedir. [12]. OTA ayrıca DNA hasarına, protein sentezi inhibisyonuna, lipid peroksidasyonuna, kanın pihtılaşmasının engellenmesine, kalsiyum homeostazi bozukluğuna, oksidatif strese ve glikojenezise neden olmaktadır $[40,66]$. IARC, OTA'yı insanlar için potansiyel kanserojen olan Grup 2B karsinojenlerine dahil etmiştir [34]. OTA, hayvanların kan, doku ve sütünde ayrıca insan sütünde tespit edilmiştir [35]. İnsan tüketimine sunulan domuz etinde de bulunan OTA'nın çok az miktarlarının bile domuz ve kuşların metabolizmalarında faaliyet gösterebildiği ortaya çıkmıştır [81]. OTA'nın kabul edilebilir günlük alım miktarı Avrupa Gıda Güvenliği Otoritesi (EFSA) ile Gıda ve Tarım Örgütü (FAO) ve Dünya Sağlık Örgütü (WHO)'nün de bağlı olduğu Gıda Katkı Maddeleri İçin Ortak Uzman Komitesi (JECFA) tarafından sırasıyla $17 \mathrm{ng} / \mathrm{kg}$ ve $14 \mathrm{ng} / \mathrm{kg}$ olarak belirlenmiştir [82,38].

\section{Sonuç}

Tarımsal geliştirmelerin daha iyi uygulandığı günümüz dünyasında mikotoksinler insanlar için ciddi sağlık riski oluşturmaktadır. Ticari olarak da satılan kurutulmuş meyvelerin, uygun olmayan şartlarda kurutulması ya da depolanması aşamalarında küf gelişimine ve dolayısıyla aflatoksin ve okratoksin A kontaminasyonuna maruz kalma potansiyeli oldukça yüksektir. Bu ürünlere aflatoksin ve okratoksin A bulaşması sonucu tüketicilerde ciddi sağlık sorunları görülmekte, ürünlerde yasal limitlerin üzerinde 
CBÜ Fen Bil. Dergi., Cilt 12, Say1 2, 327-338 s

değerlerin tespit edilmesi halinde üreticiler için de büyük ekonomik kayıplar ortaya çıkmaktadır. Bu nedenle kontamine örneklerin temizlenmesi açısından detoksifikasyon yöntemlerinin geliştirilmesi ve toksin bulaşması muhtemel üretim aşamalarında özellikle nem kontrolü yapılmasına dikkat edilmesi önerilmektedir. Literatür incelendiğinde ağırlıklı olarak incir, üzüm, kayısı, erik ve hurma üzerine çalışmalar yapıldı̆̆ görülmüş, kurutulmuş ayva, vişne ve Hindistan cevizi ile ilgili çalışmalara da rastlanılmış olsa da bunların sayısının oldukça sınırlı olduğu saptanmıştır. Diğer kurutulmuş meyvelerde sağlık üzerine toksik etkilere sahip olan aflatoksin ve okratoksin A varlığının araştırılması ile insan sağlığ1 için risk oluşturacak düzeyde toksin içerip içermediğinin belirlenmesinin literatüre katkı sağlayacağı düşünülmektedir.

\section{Referanslar}

[1] Council for Agricultural Science and Technology Mycotoxins: Risks in Plant, Animal and Human Systems Council; Ames, Iowa, USA, 2003.

[2] Desjardins, A.; Maragos, C.; Norred, W.; Pestka, J.; Philips, T.; Vardon, P.; Whitaker, T.; Wood, G.; Egmond, H. Mycotoxins: Risks in Plant, Animal and Human Systems Council; Iowa, USA, 2003; 199 pp.

[3] Magan, N.; Olsen, M. Mycotoxins in Food: Detection and Control; Woodhead Publishing Ltd: New York, 2004; 471 pp.

[4] Hussein, H.; Brasel, J. Toxicity, metabolism and impact of mycotoxins on human and animals. Toxicology, 2001; 167, 101-134.

[5] Njumbe Ediage, E.; Van Poucke, C.; De Saeger, S. A multi-analyte LC-MS/MS method for the analysis of 23 mycotoxins in different sorghum varieties: The forgotten sample matrix. Food Chemistry. 2015; 177, 397-404.

[6] Fernández-Cruz, M.L.; Mansilla, M.L.; Tadeo, J.L. Mycotoxins in fruits and their processed products: Analysis, occurrence and health implications. Journal of Advanced Research. 2010; 1, 113-122.

[7] Zinedine, A.; González-Osnaya, L.; Soriano, J.M.; Moltó, J.C.; Idrissi, L.; Mañes, J. Presence of aflatoxin M1 in pasteurized milk from Morocco. International journal of food microbiology 2007; 114, 25-9.

[8] Kumar, V.; Basu, M.S.; Rajendran, T.P. Mycotoxin research and mycoflora in some commercially important agricultural commodities. Crop Protection 2008; 27, 891-905.
CBU J. of Sci., Volume 12, Issue 2, p 327-338

[9] O' Riordan, M.J.; Wilkinson, M.G. A survey of the incidence and level of aflatoxin contamination in a range of imported spice preparations on the Irish retail market. Food Chemistry 2008; 107, 1429-1435.

[10] Prelle, A.; Spadaro, D.; Garibaldi, A.; Gullino, M.L. Co-occurrence of aflatoxins and ochratoxin $\mathrm{A}$ in spices commercialized in Italy. Food Control 2014; 39, 192-197.

[11] Drusch, S.; Ragab, W. Mycotoxins in fruits, fruit juices, and dried fruits. Journal of Food Protection. 2003; 66, 1514-1527.

[12] Cemeroğlu, B. Meyve ve Sebze İşleme Teknolojisi; Başkent Klişe Matbaacılık: Ankara, 2004; 399 pp.

[13] Marin, S.; Ramos, A.J.; Cano-Sancho, G.; Sanchis, V. Mycotoxins: Occurrence, toxicology, and exposure assessment. Food and Chemical Toxicology. 2013; $60,218-237$.

[14] Ozer, H.; Oktay Basegmez, H.I.; Ozay, G. Mycotoxin risks and toxigenic fungi in date, prune and dried apricot among Mediterranean crops. Phytopathologia Mediterranea. 2012; 51, 148-157.

[15] Delage, N.; d'Harlingue, A.; Colonna Ceccaldi, B.; Bompeix, G. Occurrence of mycotoxins in fruit juices and wine. Food Control. 2003; 14, 225-227.

[16] Kabak, B.; Var, I. Ülkemiz Açısından Sorun Olan Mikotoksinler ve Riskli Gıda Maddeleri, In Türkiye 9. G1da Kongresi; Bolu, 2006, 681-684 pp.

[17] D'Mello, J.P.F.; Macdonald, A.M.C. Mycotoxins. Animal Feed Science Technology 1997; 69, 155-166.

[18] Farkhondeh Hal, A. Erzurum'da Açıta Satılan Bazı Kurutulmus Meyveler Üzerinde Gelişen Aflatoksin Üretici Mikrofungusların Araştırılması. Atatürk Üniversitesi, Fen Bilimleri Enstitüsü, Biyoloji Anabilim Dalı, Yüksek Lisans Tezi, 2014

[19] Sabuncuoğlu, S. A.; Baydar, T.; Belma, G.; Şahin, G. Mikotoksinler: Toksik Etkileri, Degredasyonları, Oluşumlarının Önlenmesi ve Zararlı Etkilerinin Azaltılması. Hacettepe Üniversitesi Eczacılık Fakültesi Dergisi. 2008; 28, 63-92.

[20] Zinedine, A.; Mañes, J. Occurrence and legislation of mycotoxins in food and feed from Morocco. Food Control 2009; 20, 334-344.

[21] Edite Bezerra da Rocha, M.; Freire, F.D.C.O.; Erlan Feitosa Maia, F.; Izabel Florindo Guedes, M.; Rondina, D. Mycotoxins and their effects on human and animal health. Food Control. 2014; 36, 159-165.

[22] AFLATOXIN B1 | C17H12O6 - PubChem http://pubchem.ncbi.nlm.nih.gov/compound/186907 \#section=Top (accessed Sep 4, 2015).

[23] AFLATOXIN B2 I C17H14O6 - PubChem http://pubchem.ncbi.nlm.nih.gov/compound/272436 0 (accessed Sep 4, 2015). 
CBÜ Fen Bil. Dergi., Cilt 12, Say1 2, 327-338 s

[24] AFLATOXIN G1 I C17H12O7 - PubChem http://pubchem.ncbi.nlm.nih.gov/compound/14421 (accessed Sep 4, 2015).

[25] AFLATOXIN G2 | C17H14O7 - PubChem http://pubchem.ncbi.nlm.nih.gov/compound/23670 (accessed Sep 4, 2015).

[26] Iamanaka, B.T.; de Menezes, H.C.; Vicente, E.; Leite, R.S.F.; Taniwaki, M.H. Aflatoxigenic fungi and aflatoxins occurrence in sultanas and dried figs commercialized in Brazil. Food Control. 2007; 18, 454-457.

[27] Atik, İ. Aydın İlinde Doğal Olarak Kurutulan, Geleneksel ve Endüstriyel İşlenen İncirlerin Bazı Özellikleri ve Aflatoksin İçerikleri, Pamukkale Üniversitesi, Fen Bilimleri Enstitüsü, Gıda Mühendisliği Anabilim Dalı, Yüksek Lisans Tezi, 2012.

[28] Reazai, M.; Sayadi, M.; Akbarpour, B.; Mohammadpourfard, I. Safety of Dried Fruits Marketed in Tehran as Assessed by Aflatoxins Contamination. International Journal of Food Nutrition and Safety. 2014; 5, 24-30.

[29] Luttfullah, G.; Hussain, A. Studies on contamination level of aflatoxins in some dried fruits and nuts of Pakistan. Food Control. 2011; 22, 426-429.

[30] Yıkılmaz, F. Tekirdağ İlinde Satışa Sunulan Kuru İncirlerde Aflatoksin Varlığı, Namık Kemal Üniversitesi, Fen Bilimleri Enstitüsü, Gıda Mühendisliği Anabilim Dalı, Yüksek Lisans Tezi, 2007.

[31] Juan, C.; Zinedine, A.; Moltó, J.C.; Idrissi, L.; Mañes, J. Aflatoxins levels in dried fruits and nuts from Rabat-Salé area, Morocco. Food Control. 2008; 19, 849-853.

[32] Masood, M.; Iqbal, S.Z.; Asi, M.R.; Malik, N. Natural occurrence of aflatoxins in dry fruits and edible nuts. Food Control. 2015; 55, 62-65.

[33] Azaiez, I.; Font, G.; Mañes, J.; Fernández-Franzón, M. Survey of mycotoxins in dates and dried fruits from Tunisian and Spanish markets. Food Control. 2015; 51, 340-346.

[34] Trucksess, M.W.; Scott, P.M. Mycotoxins in botanicals and dried fruits: a review. Food Additives and Contaminants. 2008; 25, 181-192.

[35] International Agency for Research on Cancer Ochratoxin A. In IARC Monographs on the Evaluation of Carcinogenic Risk of Chemicals to Humans; Lyon, France, 1993; Vol. 56, pp. 489-521.

[36] Marquardt, R.R.; Frohlich, A.A. A review of recent advances in understanding ochratoxicosis. Journal of Animal Science. 1992; 70, 3968-3988.

[37] Yetkin, D.; Dalgıç, N. Balkan Nefropatisi. Türkiye Klinikleri. 1984; 4, 259-261.
CBU J. of Sci., Volume 12, Issue 2, p 327-338

[38] Fakoor Janati, S.S.; Beheshti, H.R.; Asadi, M.; Mihanparast, S.; Feizy, J. Preliminary Survey of Aflatoxins and Ochratoxin A in Dried Fruits from Iran. Bulletin of Environmental Contamination and Toxicology. 2012; 88, 391-395.

[39] Bend, J.; Bolger, M.; Kuznesof, P. M.; Larsen, J. C.; Mattia, A.; Meyland, I.; Pitt, J. I.; Resnik, S.; Schlatter, J.; Vavasour, E.; Veerabhadra Rao, M.; Verger, P.; Walker, R.; Wallin, H.; Whitehouse, B.; Abbott, P. J.; Adegoke, G.; Baan, R.; Baines, J.; Barlow, S.; Benford, D.; Bruno, A.; Charrondiere, R.; Chen, J.; Choi, M.; DiNovi, M.; Fisher, C. E.; Iseki, N.; Kawamura, Y.; Konishi, Y.; Lawrie, S.; Leblanc, J. C.; Leclercq, C.; Lee, H. M.; Moy, G.; Munro, I. C.; Nishikawa, A.; Olempska-Beer, Z.; De Peuter, G.; Pronk, M. E. J.; Renwick, a. G.; Sheffer, M.; Sipes, I. G.; Tritscher, A.; Valente Soares, L.; Wennberg, A.; Williams, G. M. Evaluation of certain food additives and contaminants. 2007; 225 pp.

[40] OCHRATOXIN A I C20H18CINO6 - PubChem http://pubchem.ncbi.nlm.nih.gov/compound/442530 (accessed Sep 4, 2015).

[41] Soyöz, M.; Özçelik, N. Okratoksin A' nın Toksik Etkileri ve Eliminasyonu. T Klin Tip Bilim. 2002; 22, 421-427.

[42] Erzurum, K. Gidalarda Mikotoksin Oluşumunu Etkileyen Faktörler. G1da. 2001; 4, 289-293.

[43] Levent, Ş.; Nas, S. Kuru İncir, Üzüm ve Kırmızıbiberlerde Mikotoksin Varlığı. Akademik Gida. 2010; 8, 24-32.

[44] Wagacha, J.M.; Muthomi, J.W. Mycotoxin problem in Africa: Current status, implications to food safety and health and possible management strategies. International Journal of Food Microbiology. 2008; 124, 1-12.

[45] Bircan, C. Incidence of ochratoxin A in dried fruits and co-occurrence with aflatoxins in dried figs. Food and Chemical Toxicology. 2009; 47, 1996-2001.

[46] Palumbo, J.D.; O’Keeffe, T.L.; Ho, Y.S.; Santillan, C.J. Occurrence of Ochratoxin A Contamination and Detection of Ochratoxigenic Aspergillus Species in Retail Samples of Dried Fruits and Nuts. Journal of Food Protection. 2015; 78, 836-842.

[47] Sharma, Y.P.; Sumbali, G.A. Natural occurrence of Ochratoxin A and toxigenic Aspergillus ochraceus strains in dry fruit slices of quinces from Jammu and Kashmir. Indian Phytopathologia. 1999; 52, 148-150.

[48] Girgin, G.; Başaran, N.; Şahin, G. Dünyada Ve Türkiye'de İnsan Sağlığını Tehdit Eden Mikotoksinler. Türk Hijyen ve Deneysel Biyoloji Dergisi. 2001; 58, 97-118.

[49] Commission of the European Communities Commission Regulation (EC) No 118/2006 of 19 
CBÜ Fen Bil. Dergi., Cilt 12, Say1 2, 327-338 s

December 2006 setting maximum levels for certain contaminants in foodstuffs. Official Journal of the European Union. 2006; 5-24.

[50] Anonim. Türk Gida Kodeksi Bulaşanlar Yönetmeliği. 29 Aralık 2011 tarihli Resmi Gazete. 2011; Vol. 28157.

[51] Anonim. Türk Gıda Kodeksi Bulaşanlar Yönetmeliği. 19 Aralık 2012 tarihli Resmi Gazete. 2012; Vol. 28502.

[52] Commission of the European Communities Commission Regulation (EC) No 165/2010 of 26 February 2010 amending regulation (EC) No $118 / 2006$ setting maximum levels for certain contaminants in foodstuffs as regards aflatoxins. Official Journal of the European Union. 2010; 8-12.

[53] Commission of the European Communities Commission Regulation (EC) No 105/2010 of 5 February 2010 amending Regulation (EC) No 1881/2006 setting maximum levels for certain contaminants in foodstuffs as regards ochratoxin A. Official Journal of the European Union. 2010; 7-8.

[54] Dini, A.; Khazaeli, P.; Roohbakhsh, A.; Madadlou, A.; Pourenamdari, M.; Setoodeh, L.; Askarian, A.; Doraki, N.; Farrokhi, H.; Moradi, H.; Khodadadi, E. Aflatoxin contamination level in Iran's pistachio nut during years 2009-2011. Food Control. 2013; 30, 540-544.

[55] Cheraghali, A.M.; Yazdanpanah, H.; Doraki, N.; Abouhossain, G.; Hassibi, M.; Ali-abadi, S.; Aliakbarpoor, M.; Amirahmadi, M.; Askarian, A.; Fallah, N.; Hashemi, T.; Jalali, M.; Kalantari, N.; Khodadadi, E.; Maddah, B.; Mohit, R.; Mohseny, M.; Phaghihy, Z.; Rahmani, A.; Setoodeh, L.; Soleimany, E.; Zamanian, F. Incidence of aflatoxins in Iran pistachio nuts. Food and chemical toxicology: an international journal published for the British Industrial Biological Research Association. 2007; 45, 812-6.

[56] Heperkan, D.; Dazkır, G.S.; Kansu, D.Z.; Güler, F.K. Influence of temperature on citrinin accumulation by Penicillium citrinum and Peniccillium verrucosum in black table olives. Toxin Reviews. 2009; 28, 180-186.

[57] Radulović, S.S.; Marković, R.V; Milić, D.D.; JakićDimić, D.P.; Šefer, D.S. Degree of mycotoxicological contamination of feed and complete feed mixtures for pigs and poultry during the period 2007-2012. on the territory of the Republic of Serbia. Matica Srpska Proceedings for Natural Sciences. 2013; 153-169.

[58] Prandini, A.; Tansini, G.; Sigolo, S.; Filippi, L.; Laporta, M.; Piva, G. On the occurrence of aflatoxin M1 in milk and dairy products. Food and Chemical Toxicology. 2009; 47, 984-91.
CBU J. of Sci., Volume 12, Issue 2, p 327-338

[59] Masoero, F.; Gallo, A.; Moschini, M.; Piva, G.; Diaz, D. Carryover of aflatoxin from feed to milk in dairy cows with low or high somatic cell counts. Animal. 2007; 1, 1344-1350.

[60] Zain, M.E. Impact of mycotoxins on humans and animals. Journal of Saudi Chemical Society. 2011; 15, 129-144.

[61] Richard, J.L. Some major mycotoxins and their mycotoxicoses-An overview. International Journal of Food Microbiology. 2007; 119, 3-10.

[62] Abdel-Wahhab, M.A.; Ahmed, H.; Hagazi, M. Prevention of aflatoxin B1-initiated hepatotoxicity in rat by marine algae extracts. Journal of Applied Toxicology. 2006; 26, 229-238.

[63] Guyonnet, D.; Belloir, C.; Suschetet, M.; Siess, M.H.; Le Bon, A.M. Mechanisms of protection against aflatoxin B1 genotoxicity in rats treated by organosulfur compounds from garlic. Carcinogenesis. 2002; 23, 1335-1341.

[64] Groopman, J.D.; Kensler, T.W.; Wild, C.P. Protective Interventions to Prevent Aflatoxin-Induced Carcinogenesis in Developing Countries. Annual Review of Public Health. 2008; 29, 187-203.

[65] Monson, M.S.; Settlage, R.E.; McMahon, K.W.; Mendoza, K.M.; Rawal, S.; El-Nezami, H.S.; Coulombe, R.A.; Reed, K.M. Response of the hepatic transcriptome to aflatoxin B1 in domestic turkey (Meleagris gallopavo). Plos One. 2014; 9, e100930.

[66] Gong, Y.Y. Dietary aflatoxin exposure and impaired growth in young children from Benin and Togo: cross sectional study. BMJ. 2002; 325, 20-21.

[67] Sedefoğlu, C. Antep Fistıklarında Okratoksin A Ve Aflatoksin Varlığının İncelenmesi, İstanbul Teknik Üniversitesi, Fen Bilimleri Enstitüsü, Gıda Mühendisliği Anabilim Dalı, Yüksek Lisans Tezi, 2013.

[68] Raiola, A.; Meca, G.; Mañes, J.; Ritieni, A. Bioaccessibility of deoxynivalenol and its natural co-occurrence with ochratoxin A and aflatoxin B1 in Italian commercial pasta. Food and chemical toxicology: an international journal published for the British Industrial Biological Research Association. 2012; 50, 280-7.

[69] Kocsubé, S.; Varga, J.; Szigeti, G.; Baranyi, N.; Suri, K.; Tóth, B.; Toldi, É.; Bartók, T.; Mesterházy, A. Aspergillus species as mycotoxin producers in agricultural products in central Europe. Matica Srpska Proceedings for Natural Sciences. 2013; 124, 13-15.

[70] Domijan, A.M.; Peraica, M.; Miletić-Medved, M.; Lucić, A.; Fuchs, R. Two different clean-up procedures for liquid chromatographic determination of ochratoxin A in urine. Journal of 
CBÜ Fen Bil. Dergi., Cilt 12, Sayı 2, 327-338 s

Chromatography B: Analytical Technologies in the Biomedical \& Life Sciences. 2003; 798, 317-321.

[71] Li, X.; Li, P.; Zhang, Q.; Zhang, Z.; Li, R.; Zhang, W.; Ding, X.; Chen, X.; Tang, X. A Sensitive Immunoaffinity Column-Linked Indirect Competitive ELISA for Ochratoxin A in Cereal and Oil Products Based on a New Monoclonal Antibody. Food Analytical Methods. 2013; 6, 14331440.

[72] Duarte, S.C.; Lino, C.M.; Pena, A. Food safety implications of ochratoxin A in animal-derived food products. Veterinary Journal. 2012; 192, 286-92.

[73] Zepnik, H.; Völkel, W.; Dekant, W. Toxicokinetics of the mycotoxin ochratoxin A in F 344 rats after oral administration. Toxicology and Applied Pharmacology. 2003; 192, 36-44.

[74] Boesch-Saadatmandi, C.; Loboda, A.; Jozkowicz, A.; Huebbe, P.; Blank, R.; Wolffram, S.; Dulak, J.; Rimbach, G. Effect of ochratoxin A on redoxregulated transcription factors, antioxidant enzymes and glutathione-S-transferase in cultured kidney tubulus cells. Food and Chemical Toxicology. 2008; 46, 2665-71.

[75] Palma, N.; Cinelli, S.; Sapora, O.; Wilson, S. H.; Dogliotti, E. Ochratoxin A-induced mutagenesis in mammalian cells is consistent with the production of oxidative stress. Chemical Research in Toxicology. 2007; 20, 1031-1037.

[76] Reddy, L.; Bhoola, K. Ochratoxins-food contaminants: impact on human health. Toxins. 2010; 2, 771-779.

[77] Kahraman, H. Involvement Of Autophagy In Ochratoxin-A (OTA)-Mediated Toxicity In HK-2 Cell Line, Boğaziçi Üniversitesi, Fen Bilimleri Enstitüsü, Moleküler Biyoloji ve Genetik Anabilim Dalı, Yüksek Lisans Tezi, 2011.

[78] Malir, F.; Ostry, V.; Novotna, E. Toxicity of the mycotoxin ochratoxin A in the light of recent data. Toxin Reviews. 2013; 32, 19-33.

[79] Stoev, S. D. The role of ochratoxin A as a possible cause of Balkan endemic nephropathy and its risk evaluation. Veterinary and Human Toxicology. 1998; 40, 352-360.

[80] Tatu, C.A.; Orem, W.H.; Finkelman, R.B.; Feder, G.L. The etiology of Balkan endemic nephropathy: Still more questions than answers. Environmental Health Perspectives. 1998; 106, 689-700.

[81] Gremmels, J.F. Mycotoxins: Their implications for human and animal health. Veterinary Quarterly 1999; 21, 115-120.

[82] Journal, T.E. Guidance of the Scientific Committee on a request from EFSA related to Uncertainties in Dietary Exposure Assessment. The EFSA Journal. 2006; 438, 1-54. 